\title{
Reduction of the capture width of wave energy converters due to long-term seasonal wave energy trends
}

\author{
Alain Ulazia $^{\mathrm{a}, *}$, Markel Penalba ${ }^{\mathrm{b}, \mathrm{d}}$, Gabriel Ibarra-Berastegui ${ }^{\mathrm{c}, \mathrm{f}}$, John Ringwood ${ }^{\mathrm{d}}$, Jon Sáenz ${ }^{\mathrm{e}, \mathrm{f}}$ \\ ${ }^{a}$ Department of NE and Fluid Mechanics, University of the Basque Country (UPV/EHU), Otaola 29, 20600 Eibar, Spain \\ ${ }^{\mathrm{b}}$ Department of Mechanical and Industrial Production, Mondragon University, Loramendi 4 Apdo. 23, 20500 Arrasate, Spain \\ ${ }^{\mathrm{c}}$ Department of NE and Fluid Mechanics, University of the Basque Country (UPV/EHU), Alda. Urkijo, 48013 Bilbao, Spain \\ ${ }^{\mathrm{d}}$ Centre for Ocean Energy Research, Maynooth University, Maynooth, Co. Kildare, Ireland \\ ${ }^{\mathrm{e}}$ Department of Applied Physics II, University of the Basque Country (UPV/EHU), B. Sarriena s/n, 48940 Leioa, Spain \\ ${ }^{\mathrm{f}}$ Joint Research Unit (UPV/EHU-IEO) Plentziako Itsas Estazioa, University of Basque Country (UPV/EHU), Areatza Hiribidea 47, 48620 Plentzia, Spain
}

\section{A R T I C L E I N F O}

\section{Keywords:}

Wave energy variability

Capture width ratio

ERA-20C

Wave energy conversion

Seasonality

\begin{abstract}
A B S T R A C T
This paper presents a pioneering attempt to evaluate the impact of long-term seasonal wave energy trends on hydrodynamic capture by wave energy converters (WECs) over the 20th century. The ERA20c reanalysis generated by the European Centre for Medium-Range Weather Forecasts is calibrated against the ERA-Interim reanalysis via the quantile matching technique, and validated against buoy measurements across the Northeast Atlantic Ocean. The study focus is the seasonal variation of wave resources over the 20th century, so the calibration is performed using seasonally classified reanalysis and measured data. Results show that wave energy flux increased to 3 and $2 \mathrm{~kW} / \mathrm{m}$ per decade in winter and spring/autumn, respectively, and that the frequency of off-limit events, defined as sea-states with significant wave height of over $5 \mathrm{~m}$, has doubled over the 20 th century. The impact of such wave energy trends is analysed in this paper using an oscillating wave surge converter, which shows steadily increasing power absorption over the 20th century. However, as a result of higher decadal trends and the increase in off-limit events, the hydrodynamic efficiency of the WEC, referred to as the capture width ratio, decreases up to $20 \%$.
\end{abstract}

\section{Introduction}

Due to the necessity to reduce greenhouse emissions, the importance of renewable energy sources, mainly wind and solar energy, has significantly increased over recent decades. The untapped potential of ocean waves, estimated to be about $32.000 \mathrm{TWh} /$ year [1], is also expected to significantly contribute to the future energy mix, where renewable energy sources will surely play a crucial role.

There are several different wave energy converters (WECs) based on different working principles [2], but none of these prototypes has yet demonstrated commercial viability. As a matter of fact, very few cases have contributed to the national electricity grids. The Mutriku Wave Energy Plant, located in the Bay of Biscay, is one of the exceptions, which uses the oscillating water column technology to absorb power from ocean waves and deliver electricity to the national grid [3].

The main challenge for the development of successful WECs is reducing the levelized cost of energy (LCOE), which should be reduced, at least, by a factor of 2, according to Ref. [4]. In this respect, several different aspects are essential, such as energy maximising control strategies [5], power take-off (PTO) systems [6], survivability of WECs [7], and construction, deployment and maintenance costs [8]. In addition, precise characterisation of the wave energy resource is crucial for accurately designing WECs and minimising the LCOE.

Traditionally, the wave resource of a given location is characterised utilising:

1. The wave energy flux and its inter-annual variability (analysing the seasonal cycle),

2. The bi-dimensional probability density function, or scatter diagram, given by the wave period and the wave height, and

3. The probability of occurrence of off-limit events, where the WEC needs to activate its survival mode.

In general, wave data from previous one, two or three decades are used for assessing the resource and power production capabilities of WECs in a given location [9-15]. However, by only considering data

\footnotetext{
* Corresponding author.

E-mail addresses: alain.ulazia@ehu.eus (A. Ulazia), mpenalba@eeng.nuim.ie (M. Penalba), gabriel.ibarra@ehu.eus (G. Ibarra-Berastegui), john.ringwood@eeng.nuim.ie (J. Ringwood), jon.saenz@ehu.eus (J. Sáenz).
} 
from recent decade(s), historical variations and trends of the resource are not taken into account, which in certain regions could constitute an important issue due to the effects of climatic change or other synoptic causes. This means that the resource characteristics employed in WEC design, including all the different components (such as the PTO system, mooring lines and transmission electricity cables), and the real ocean conditions where the WEC actually absorbs energy, may be significantly different.

In previous studies by the authors, a fourth aspect was demonstrated to be important: historical wave energy trends. In this respect, as demonstrated in Refs. [16-18], developers should not only consider past data to characterise the wave energy resource of a given location, but should also understand the wave trends and predict the future wave resource where the WEC will actually be deployed. The longer the period of past data, the better the understanding of the resource, and the more precisely can the future resource be predicted. However, seasonal analysis, which includes these resource variations over the 20th century for each of the seasons (summer, autumn, winter and spring), is yet to be completed. Thus, the main objective of this paper is to extend the previous papers in Chile, Gulf of Biscay and Ireland by the authors $[17,18]$ in two ways. First, the study area is extended, incorporating areas such as Northern areas from the Bay of Biscay and new buoys (Bilbao-Vizcaya, Britanny and M1). Additionally, the study is extended by performing the analysis stratifying the data seasonally. This is relevant, since previous studies $[3,19]$ have shown that there exist differences in the wave climate over the area at different seasons.

To make reliable estimations of the distribution of climate variables in a given region, the World Meteorological Organization [20,21] proposes using a minimum of 30 years of data. The present study includes data from the past 100 years, divided into five periods referred to as do-decades in the following report. In fact, a do-decade is considered the standard lifespan of WECs. Therefore, several periods or lifespans are considered to evaluate the historical evolution of the wave energy resource, identify trends, and compute the energetic differences between these lifespans. Shifts in wave height and wave period combinations leading to these changes are also considered. The authors think that the study of these five do-decades of the 20th century can offer a good account of variation of the wave energy available in the Northeast Atlantic Ocean.

Thus, this analysis does not only include the historical trends of the average wave energy flow, but also the trends of the inter-annual variability of this wave energy resource, focusing in particular on differences between the mildest (summer) and most powerful (winter) seasons. This is because the difference between these seasons limits the profitability threshold of WECs [22]. Proper characterisation of the existing sea-states and their frequency of occurrence is needed to correctly select a WEC that will maximize the overall electricity output in a given location. This involves the use of the power matrices of realistic WEC devices.

The remainder of the paper is organised as follows: Section 2 presents a comprehensive literature review of the different studies where wave resource variations have been analysed. Section 3 describes the data and the methodology used in the study. Section 4 introduces the mathematical model used to assess the power production capabilities, the WEC selected for the analysis, and the capture width ratio to evaluate the hydrodynamic efficiency of the selected WEC. Section 5 presents the results and Section 6 offers discussion of the results. Section 7 draws the final conclusions.

\section{Literature review}

Although the importance of the estimation of these energy trends is clear for the future of the wave energy industry, previous studies in the literature have been focused mainly on trends of the wave height. These studies can use in situ measurements from buoys [23], wave observations from ships [13,24-27], satellite altimeters [28,29], and model and reanalysis datasets [30-39]. However, these studies estimate decadal or yearly trends without analysing the seasonal trends separately. As the authors will show, the main seasonal contribution to the decadal positive trend of wave energy in the last century over the Northeast Atlantic is made by data from winter and autumn, while summer data show very small increments.

Regarding the data sources from models and reanalyses, although the seasonal trends are not computed, one recent work that is similar to the one presented here, is a global study on wave energy resources by Zheng et al. [30,32]. Zheng used a swell index and, instead of the whole 20th century, analysed only 45 years via the reanalysis ERA40 (previous to ERA-Interim-WAM), which is used in the present study as the basis for calibrating the ERA20c (see Section 3). In the global maps presented in Refs. [30,32] on the trends in wave energy flux, wind waves and swell are separated, and historical trends off the Portuguese coast, North coast of the Iberian Peninsula, and west coast of France are not presented, because the results are not 'statistically significant'. In any case, off the west coast of Ireland and south of Iceland, Zheng identifies a significant hot spot with an increment of $9 \mathrm{~kW} / \mathrm{m} /$ decade.

In a similar study in the North Atlantic, Bertin et al. [33] have also used the ERA20c reanalysis for the estimation of the wave height linear trend, and its correlation with the North Atlantic Oscillation. They have found a positive trend between $2.5 \mathrm{~cm} /$ decade and $5 \mathrm{~cm} /$ decade in the interior waters west of France and north of the Iberian peninsula, and $7.5 \mathrm{~cm} /$ decade in a zonal line towards the area west of Ireland.

Another important recent global study using satellite altimetry covers a period of 23 years (1985-2008), and considered wave and wind trends [29]. According to them, in the study area of this paper the trends are generally neutral, with a weak positive trend between 0 and $0.25 \%$ per year west of Ireland, that is, up to $5 \mathrm{~cm}$ increase per decade considering a typical $2 \mathrm{~m}$ mean wave height [29, Fig. 1]. On the other hand, considering visual observations of waves from ships, Gulev et al. [24-26] computed positive trends of $4-8 \mathrm{~cm}$ /decade over the study area. In any case, the seasonality is not mentioned in these works and wave height is the only parameter studied. The evolution of the energy was not computed, because most previous studies have not examined the trends of wave periods, which is vital for the analysis of the wave energy resource.

There are some atmospheric teleconnection patterns that affect the

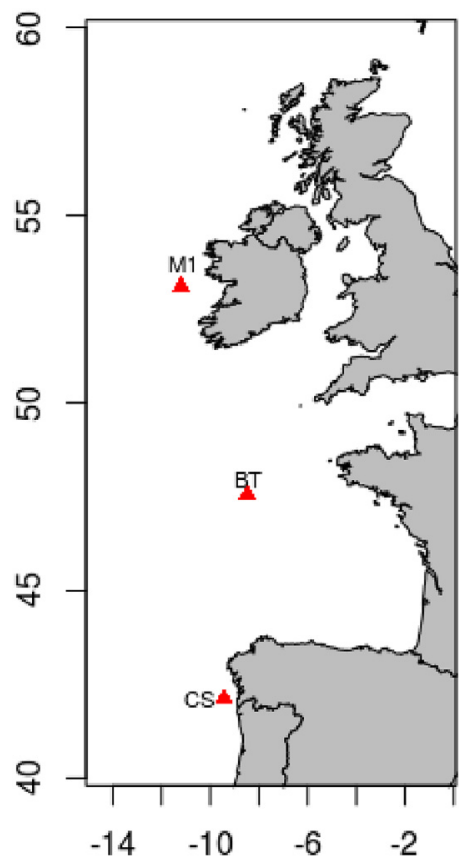

Fig. 1. The area of study and the three buoys. 
North Atlantic region. The most important pattern in the study area, the North Atlantic Oscillation (NAO), consists of a North-South dipole in the pressure field which, in its positive phases, produces increased westerly winds and, therefore, increased wave power over the northern regions of the Bay of Biscay [40-42]. However, other teleconnection patterns over the area have also shown their relevance in the Atlantic pressure field and Atlantic cyclone-tracks [43,44]. These variations produce significant impact on precipitation and temperature [45], but also on wave climate over the area.

In this way, Reguero et al. [31] study the monthly correlation of wave energy using climate indexes: the NAO, the Scandinavian index (SCA) and the East Atlantic Pattern (EA) present the strongest influence on the Atlantic wave power. In fact, the influence of the NAO in the northeast Atlantic has long been associated with swell variations according to ship data [25]. In their decadal study (2003-2012), Neill et al. [12] also show the relevance of the NAO pattern to understand the temporal behaviour of the wave energy resource in Orkney (Scotland) and the need to properly estimate this resource using longer periods. This emphasizes the importance of our previous contributions, which are analyses of the historical wave energy trends within the context of energy production [16-18].

Other authors [13-15,46] also present recent seasonal studies on wave energy in different locations in the world (Tartous, Spitsbergen, Baltic Sea, and Indian seas during the southwest monsoon season), but they do not implement a specific device as done in this case or the case of $[12,22,47]$ to estimate the practical energy production using specific WECs or even arrays of WECs. However, their periods of analysis were three or four decades at most, and the question about the trends is therefore obviated.

In the studies where the performance of one or more WECs is evaluated, the resource is, in general, considered static, that is, historical wave trends are neglected. Although only one decade is used [12], estimates the seasonal wave energy production in Orkney using a specific device (practical production), as done in the present study. They use the power matrix of the $750 \mathrm{~kW}$ Pelamis WEC to estimate and compare the variability of practical energy production versus the theoretical resource during winter. Obviously, the variability of the practical resource is less than the variability of the theoretical resource, because the Pelamis device shifts into survival mode during extreme sea events. In Ref. [48], these considerations about the doubtful performance of very energetic sites elicited the remarks: less energetic wave sites should also be considered, since such environments offer the benefit of a more consistent wave resource, partly offsetting the significant inter-annual variability that characterises high energy wave sites.

This comparison between practical production and theoretical resource will also be an essential idea in this study, although variability analysis is not the main objective. Unfortunately, due to the lack of electricity generation data, the capacity factor cannot be used in this study, and a ratio between the theoretical power stored in ocean waves and the hydrodynamic power absorbed by the WEC, is used instead. This ratio is known as the capture width ratio (CWR) and is further described in Section 4.2.

In Ref. [49], the CWR is calculated using the final electric power yielded by a hypothetical WEC (instead of the mechanical power) and this indicator is calculated for 20 locations near European islands. In this study, authors give their results both for winter season alone, and also for the average of the seasons. In other studies, such as that by Ref. [50], the CWR for different devices and locations is calculated under the assumption of a static image of the wave energy resource in the selected location.

\section{Data and methodology}

\subsection{Data}

\subsubsection{ERA-20C and ERA-Interim}

Two reanalyses of the European Centre for Medium-Range Weather Forecasts (ECMWF) are used with an intersection period of 32 years (1979-2010):

- ERA20c (henceforth ERA20) [51]. This reanalysis is ECMWF's first atmospheric reanalysis spanning the whole 20th Century and it assimilates observations of surface pressure and surface marine winds from ISPDv3.2.6 and ICOADSv2.5.1 [52] by means of a 4D-Var analysis with coupled atmospheric, land-surface and ocean-waves models, as described in ECMWF's IFS version Cy38r1 assimilation system. The quality of ERA20 data is affected, particularly in regions of sparse observational coverage [51], so it is better in the Northern Hemisphere than in the Southern Hemisphere. However, ERA20 has been used globally in the study of historical wave and coastal evolution [53-55]. ERA20's spatial resolution is approximately $125 \mathrm{~km}$ and wave parameters can be obtained 3-hourly.

- ERA-Interim (henceforth ERAI) [56]. This is a global reanalysis from 1979 until now. The data assimilation method is 12-h 4D-Var and is based on a fixed version of a numerical weather prediction (NWP) system (IFS - Cy31r2). The fixed version ensures that no spurious trends are caused by changes in the assimilation system. However, changes in the observation system can create such trends [57,58], whilst this problem has been reduced in the shorter time covered by ERAI [59]. The wave model is based on the Wave Modelling Project (WAM) approach [60], and, as a relevant contribution to the authors' purpose (wave energy that is proportional to wave period), the new version has reduced error in the wave period against buoy data compared with previous ERA40 error [61]. The spatial resolution is approximately $75 \mathrm{~km}$ and wave parameters can be obtained 6-hourly.

The observations assimilated by ERAI and ERA20 differ both in type of observations (satellite radiances, for instance, are not assimilated by ERA20) and also in the physical magnitudes that are being assimilated (temperatures or vertical soundings are not assimilated in ERA20, but they are assimilated in ERAI). Thus, there exist substantial biases between analysis fields from both reanalyses or ERA20 and in situ observations [62]. The fact that climate models show substantial biases in fields (such as precipitation) that must be removed before the effective use of precipitation fields in impact studies, has long been recognized. See, for instance Ref. [63], and references therein. Studies applying quantile-matching techniques to seasonal subsamples have also demonstrated robustness at that scale [64] for daily precipitation. As explained below in Section 2.2, this is the technique selected in this paper.

Therefore, in order to have the same time resolution in the data series, 6-hourly data have been chosen for ERA20 in the calibration, and also for the buoys in the validation procedure.

\subsubsection{Buoy data}

Fig. 1 presents the study area and the three buoys chosen from the resources offered by the Spanish Port Authority [65] (Cabo Silleiros in Galicia), the MetOffice UK [66] (Brittany) and the Irish Marine Institute [67] (in Galway Bay). As can be seen in Fig. 1, these buoys have been strategically selected to obtain extended representation of the Northeast Atlantic shore. Thus, this area includes the Bay of Biscay, the Celtic Sea, the Irish Sea, the Inner Seas and part of the English Channel.

Table 1 presents the buoy positions and the distance to the nearest ERA20 grid point, from which validations considering the seasons have been performed independently. In the last column the period of validation between the data in the reanalysis and those from the three 
Table 1

Buoys on the bay of biscay.

\begin{tabular}{llll}
\hline Buoy, abbreviation & Position (lon,lat) & Nearest gridpoint & Validation Period \\
\hline 1. Brittany, BT & $(-8.47,47.55)$ & $51.9 \mathrm{~km}$ & $1998-2010$ \\
2. Cabo Silleiro, CS & $(-9.43,42.12)$ & $65.5 \mathrm{~km}$ & $1998-2010$ \\
3. Galway, M1 & $(-11.2,53.1)$ & $27 \mathrm{~km}$ & $2003-2010$
\end{tabular}

buoys is shown.

\subsection{Methodology}

\subsubsection{Wave energy flux}

To obtain the WEF time series from the series of Significant Wave Height $\left(H_{s}\right)$ and Mean Wave Period $\left(T_{m}\right)$ data of buoys and reanalyses, a well-known equation has been applied with corrections for Peak Period $\left(T_{p}\right)$, as explained in authors' previous work, by means of the Wave Period Ratio [16]:

$W E F=0.49 H_{s}^{2} T_{m} ;$

\subsubsection{Seasonally classified calibration}

The calibration or bias correction method used in this seasonal study is usually called 'classified quantile-matching'. This general method compares models and reanalyses to observations, or different models at different spatial and temporal scales. It is well-known in meteorology and climatology for its use to calibrate temperature, precipitation, wind speed or other parameters [68-72]. In the particular case of quantile-matching, several other names for it can be found in the literature, such as 'probability mapping' [73], 'quantile-quantile mapping' [74,75], 'statistical downscaling' [76] and 'histogram equalization' [77].

The idea of classification is also used to achieve more sophisticated calibrations. For example, in the case of temperature and precipitation the events are classified according to their intensity (rainy days, storms or heat waves would be extreme events), and it is typical to establish an order of four or five classification intervals from low intensity events to high intensity ones. In this way, instead of a unique transfer function for the time series, the authors have one transfer function for each interval of the classification. In the case of wind speed this classification can be directional (i.e. four quadrants: NE, SE, SW and NW), to obtain a proper transfer function for each direction interval (four functions), instead of only one. This is called 'wind rose bias correction' [78].

In this paper, this classification is seasonal, so four transfer functions are obtained for winter, spring, summer and autumn. In the previous works [16-18], the authors did not use any kind of classification, and consequently, it can be said that an improved quantile-matching calibration is applied in this case. In any case, comparison of the quality of these calibrations (with and without intrinsic classifications) is beyond the scope of this work. However, the authors will show that the validations in the seasons of the calibrated data (cERA20) against the buoy data are significantly improved with respect to the non-calibrated original data of ERA20.

In Ref. [71] this procedure is also developed for wind speed without classification between the two reanalyses, ERA20 and ERAI. As far as we know, it is the first work about the implications of long-period trends on renewable energies (wind industry in this case). Fig. 2 illustrates the steps of the calibration procedure:

1. The same probability at the Cumulated Density Function (CFD) vertical axis cuts the curves of ERA20 and ERAI at the same level;

2. For that probability, two values of the wave energy flux (horizontal axis) are obtained, one for ERA20, and the other for ERAI;

3. So, a transfer is created from the ERA20's non-calibrated value (ncv) towards the ERAI's calibrated value (cv), that is, the base of the

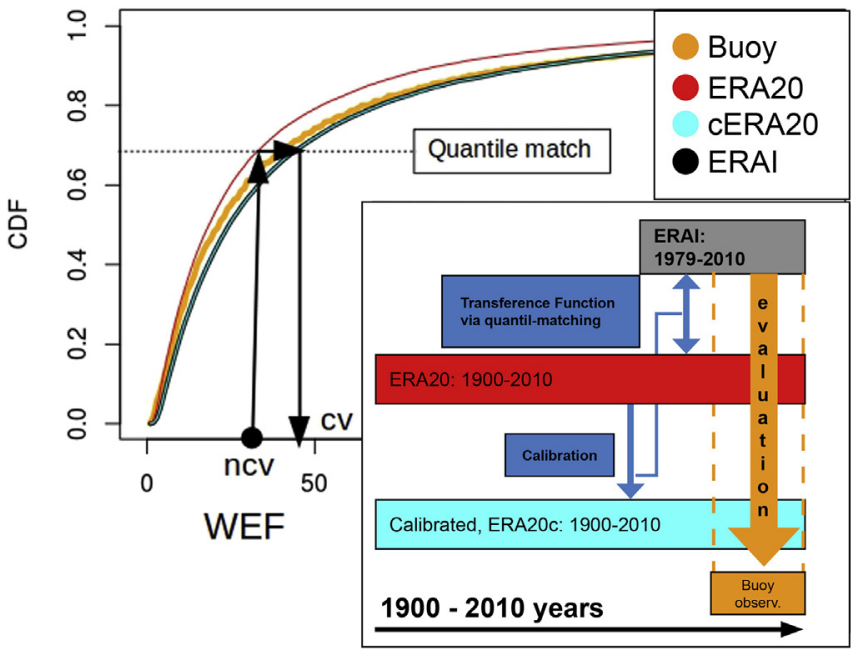

Fig. 2. Schema of the quantile-matching procedure and validation versus buoys.

calibration;

4. This is established for all the distribution of probabilities generating a transfer function;

5. If this transfer function is applied to all the values of ERA20 the calibrated curve cERA20 can be represented;

6. Finally, the authors can verify if the calibrated new curve is nearer the observation curve of the buoy.

In the same Fig. 2, there is a flow chart illustrating the time periods of each reanalysis, the calibration process between ERA20 and ERAI to obtain the calibrated cERA20 100-year data, and the validation of the three datasets versus the buoys.

\subsubsection{Validation against buoys}

Seven statistical indexes are used for the validation of the calibration procedure against the three buoys during the seasons, that is, to compare the non-calibrated data of ERA20 with the calibrated cERA20 data and the calibration base of ERAI:

1. The Pearson's correlation of the wave energy flux WEF (see 4.2);

2. The bias of the WEF with respect to the buoys' counterpart. The authors have seen that in this case, that bias is more significant than the root mean square error or other absolute errors. This is because it allows measurement of underestimation or overestimation, if they occur.

3. The $95 \%$ percentile, the median, and the $5 \%$ percentile are used to compare the adjustment of the quantiles and the values of the extreme cases for the WEF.

4. Finally, the probability of occurrence of significant wave heights above 5 and $7 \mathrm{~m}$ is used $\left(\mathbf{P r}_{H_{\mathrm{s}}>5 \mathrm{~m}}, \mathbf{P r}_{H_{\mathrm{s}}>7 \mathrm{~m}}\right)$. Although the WEF numbers are too high, this reference is usually used for the adoption of survival mode by the wave energy converter. So the authors have introduced this upper limit for the validation, although it is not computed in terms of the WEF.

\subsubsection{Seasonal trend maps}

After the validation, the seasonal WEF trend maps in $\mathrm{kW} / \mathrm{m}$ per decade in winter, spring, summer and autumn were drawn over the study area, calibrating monthly data of ERA20 at each grid point against the monthly data from the nearest ERAI grid point. As mentioned, a proper transfer function was obtained for each season for classifying the time series in four categories. Before computing the trends, historical monthly averages were subtracted from the series to produce monthly anomalies. The trends are computed using the non- 


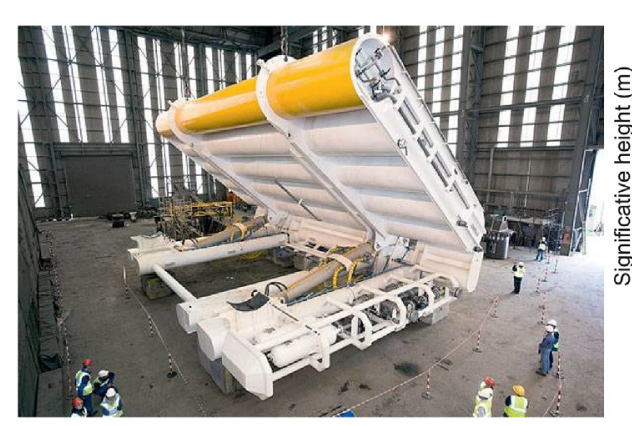

(a)

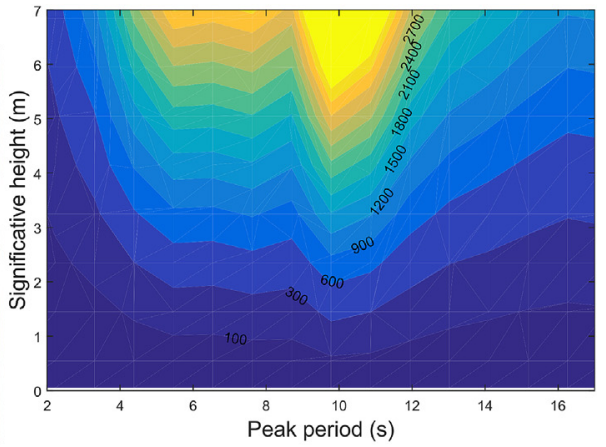

(b)

Fig. 3. The Oyster OWSC by Aquamarine Ltd. (a) and its power matrix (b).

Table 2

Validation at the three buoys in winter.

\begin{tabular}{|c|c|c|c|c|c|c|c|c|c|c|c|c|}
\hline \multirow[t]{2}{*}{ Winter } & \multicolumn{4}{|c|}{ Cabo Silleiro } & \multicolumn{4}{|c|}{ Britanny } & \multicolumn{4}{|l|}{ M1 } \\
\hline & ERAI & ERA20 & cERA20 & Obs. & ERAI & ERA20 & cERA20 & Obs. & ERAI & ERA20 & cERA20 & Obs. \\
\hline Correlation & 0.94 & $0.93^{*}$ & $0.93^{*}$ & - & 0.82 & $0.82 *$ & $0.82^{*}$ & - & 0.94 & $0.93^{*}$ & $0.93^{*}$ & - \\
\hline $\operatorname{Bias}(\mathrm{kW} / \mathrm{m})$ & -3.3 & -15.6 & -3.4 & - & 2.0 & -18.0 & 2.4 & - & 1.4 & -16.9 & 1.2 & - \\
\hline $95 \%$ perc. $(\mathrm{kW} / \mathrm{m})$ & 101.6 & 62.1 & 100.7 & 120.5 & 259.0 & 192.0 & 251.5 & 278.9 & 217.6 & 158.3 & 217.5 & 221.8 \\
\hline Median $(\mathrm{kW} / \mathrm{m})$ & 16.5 & 8.7 & 16.3 & 15.2 & 53.7 & 40.3 & 54.0 & 46.0 & 32.3 & 21.9 & 32.3 & 31.6 \\
\hline $5 \%$ perc. $(\mathrm{kW} / \mathrm{m})$ & 3.4 & 1.7 & 3.5 & 2.4 & 10.9 & 8.7 & 11.7 & 7.2 & 5.6 & 3.8 & 5.6 & 4.5 \\
\hline $\mathbf{P r}_{H_{S}>5 m}(\%)$ & 1.26 & 0.35 & 1.31 & 2.06 & 4.37 & 3.07 & 4.40 & 3.07 & 7.18 & 4.97 & 7.23 & 6.15 \\
\hline $\operatorname{Pr}_{H_{S}}>7 m(\%)$ & 0.08 & 0.00 & 0.08 & 0.44 & 0.86 & 0.50 & 0.83 & 0.60 & 0.78 & 0.33 & 0.78 & 1.53 \\
\hline
\end{tabular}

parametric Theil-Sen $[79,80]$ method, which fits a line through a series of points using the median of the slopes of all lines through pairs of points. The significance of the trend at each grid point was evaluated at a 95\% confidence level using bootstrap resampling with 1000 samples.

\section{Wave-structure hydrodynamic interaction modelling}

Wave-structure hydrodynamic interactions (WSHIs) of WECs can be modelled via several different approaches, including linear and nonlinear representations of WSHIs, as described in Ref. [81]. Precise hydrodynamic models are essential to predict adequately the behaviour and power absorption of WECs; however, the optimum modelling approach varies with the type of WEC. The impact of long-term seasonal wave trends are presented in this paper for an oscillating wave surge converter (OWSC), described in detail in Section 4.1. Following the suggestions presented in Ref. [81], the WSHIs of OWSCs can be represented with reasonable accuracy using a mathematical model based on linear potential theory, and then adding viscous effects externally.

Hence, using the methodological background of [17] but introducing new relevant aspects, the power absorption capabilities of the OWSC are analysed via a time-domain hydrodynamic model based on Cummins' equation [82], as follows.

$$
\begin{aligned}
\left(M+\mu_{\infty}\right) \ddot{x}(t)= & F_{\text {ex }}(t)-K_{H} x-\int_{0}^{t} K_{\text {rad }}(t-\tau) \dot{x}(\tau) d t+F_{\text {visc }}(t) \\
& +F_{P T O}(t)+F_{\text {EndStop }}(t),
\end{aligned}
$$

where $M$ is the device mass and $\mu_{\infty}$ is the added-mass at infinite frequency, and $x(t), \dot{x}(t)$ and $\ddot{x}(t)$ the displacement, velocity and acceleration of the device, respectively. $F_{e x}(t)$ is the excitation force, $K_{H}$ the hydrostatic stiffness, $K_{\text {rad }}$ the radiation impulse response, $F_{v i s c}$ the viscous force, $F_{\text {PTO }}$ the power take off (PTO) force, and $F_{\text {EndStop }}$ the force that reproduces the end-stop effect of the PTO mechanism. The hydrodynamic coefficients $\mu_{\infty}, F_{e x}, K_{H}$ and $K_{r a d}$ are obtained from the boundary element method code NEMOH [83].

Viscous effects are especially relevant for OWSCs and are modelled, in the vast majority of cases, using Morison's equation [84], with a quadratic damping term known as the drag coefficient $\left(C_{D}\right)$. The value of the drag coefficient for the OWSC device is determined to be $C_{D}=8$ based on different literature studies that use similar models for power production assessment, e.g. Ref. [85].

$F_{v i s c}(t)=\frac{1}{2} \rho C_{D} A_{D}\left(\dot{x}-V_{0}\right)\left|\dot{x}-V_{0}\right|$

where $\rho$ is the water density, $A_{D}$ the characteristic area of the WEC and $V_{0}$ the velocity of the undisturbed flow.

Finally, the PTO is modelled as a spring-damper system, neglecting the dynamics and losses of the different components in the PTO system. Although these dynamics and losses are shown to be vital to accurate prediction of generated power [86,87], the present paper is focused more on the impact of resource variation on the energy absorption capabilities of WECs. Therefore, the dynamics and losses of the PTO system can be neglected, by representing the PTO force as follows,

$F_{\text {РTO }}(t)=-K_{\text {РTO }} x-B_{\text {РTO }} \dot{x}$

where $B_{P T O}$ and $K_{P T O}$ are the linear PTO damping and stiffness. The damping term is the dissipative term that absorbs energy from ocean waves, while the stiffness is required to increase absorbed power by bringing the device closer to resonance. This linear PTO model is also known as reactive control. Coefficients $B_{Р T O}$ and $K_{Р T O}$ have been optimised for each sea-state to maximize the energy absorption. The optimization is carried out via the exhaustive search algorithm, ensuring that the optimal value is always the global maximum.

Although dynamics and losses of the PTO system are irrelevant for absorbed power assessment, the constraints of the PTO system, such as displacement or PTO force constraints, can significantly affect the power absorption of WECs. Therefore, both displacement and PTO force constraints, are implemented in the mathematical model, similarly to that by Ref. [85].

\subsection{Oscillating wave surge converter}

The WEC selected to evaluate the impact of seasonal wave trends on the power absorption of WECs is an OWSC inspired in the Oyster device 
Table 3

Validation at the three buoys in summer.

\begin{tabular}{|c|c|c|c|c|c|c|c|c|c|c|c|c|}
\hline \multirow[t]{2}{*}{ Summer } & \multicolumn{4}{|c|}{ Cabo Silleiro } & \multicolumn{4}{|c|}{ Britanny } & \multicolumn{4}{|l|}{ M1 } \\
\hline & ERAI & ERA20 & cERA20 & Obs. & ERAI & ERA20 & cERA20 & Obs. & ERAI & ERA20 & cERA20 & Obs. \\
\hline Correlation & 0.90 & $0.87^{*}$ & $0.87 *$ & - & 0.75 & $0.76^{*}$ & $0.76^{*}$ & - & 0.92 & $0.91^{*}$ & $0.91 *$ & - \\
\hline Bias $(\mathrm{kW} / \mathrm{m})$ & 0.0 & -5.6 & -0.4 & - & -0.5 & -5.5 & -1.4 & - & -1.8 & -8.7 & -1.3 & - \\
\hline $95 \%$ perc. $(\mathrm{kW} / \mathrm{m})$ & 34.0 & 18.4 & 31.9 & 36.6 & 50.6 & 36.1 & 48.4 & 59.3 & 77.2 & 53.6 & 77.6 & 87.6 \\
\hline Median $(\mathrm{kW} / \mathrm{m})$ & 7.7 & 3.8 & 7.6 & 6.9 & 10.3 & 7.5 & 10.0 & 9.9 & 15.0 & 9.8 & 14.8 & 12.5 \\
\hline $5 \%$ perc. $(\mathrm{kW} / \mathrm{m})$ & 2.4 & 1.2 & 2.5 & 1.5 & 3.1 & 2.2 & 3.1 & 2.1 & 4.2 & 2.6 & 4.0 & 2.3 \\
\hline $\mathbf{P r}_{H_{S}>5 m}(\%)$ & 0.02 & 0.00 & 0.02 & 0.08 & 0.16 & 0.09 & 0.14 & 0.09 & 0.29 & 0.13 & 0.28 & 0.44 \\
\hline $\mathbf{P r}_{H_{S}>7 m}(\%)$ & 0.00 & 0.00 & 0.00 & 0.00 & 0.04 & 0.02 & 0.04 & 0.00 & 0.01 & 0.00 & 0.01 & 0.03 \\
\hline
\end{tabular}

designed by Aquamarine Power Ltd. [88], as illustrated in Fig. 3 (a). Here the authors present a schematic summary and further details, including geometrical characteristics and other properties of the device (drag and damping coefficients, etc), can be found in Ref. [17].

An estimation of the annual mean power production (AMPP) of the OWSC in a given location can be calculated by combining the power matrix of the device and the scatter diagram or probability density function (PDF) of the selected location. Fig. 3(b) illustrates the power matrix of the OWSC. The scatter diagrams for the different locations presented in Table 1 are shown in Fig. 6 for the 1980-2000 do-decade.

\subsection{Capture width ratio}

An alternative to the AMPP measure for evaluating power absorption capabilities of a device is the capture width (CW), that is, the ratio between the absorbed energy and the energy available in ocean waves:

$C W=\frac{P_{a b s}}{J}$

where $J$ is the mean WEF given in power per wave-front $(\mathrm{kW} / \mathrm{m})$. The CW measure was first introduced in Ref. [89] and has a dimension analogous to length or width. In fact, $C W$ is interpreted as the wavefront width completely absorbed by the WEC from the incoming wave.

A variation of the $C W$ is the capture width ratio $(C W R)$, which reflects the efficiency of the hydrodynamic absorption of a WEC. The capture width ratio is defined as the ratio between $C W$ and the characteristic length of the WEC $(B)$, and is given as

$C W R[\%]=\frac{C W}{B} \times 100=\frac{P_{a b s}}{J B} \times 100$.

Hence, $C W R$ represents the fraction of wave energy that is absorbed by a WEC from the energy available within the extension of the WEC. Although it is considered hydrodynamic efficiency, it should be noted that, due to the antenna effect, the CWR can be greater than $100 \%$ [4].

The characteristic length $B$, which is commonly used in the calculation of the $C W R$ of a WEC is, in general, the width of the WEC, which in the case of the present paper is the width of the OWSC: $B=26 \mathrm{~m}$. A classification of different devices based on their $C W R$ is presented in Ref. [50].

The objective of the present paper was to study the variation of the $C W R$ measure over the 20th century for summer and winter wave climates. To that end, the $C W R$ is analysed under realistic conditions (i.e. for irregular wave conditions) and for a WEC with displacement and force constraints. Hence, the annual average capture width ratio $\left(C W R_{A M P P}\right)$ is used, as suggested in Ref. [4]. It is given as

$C W R_{A M P P}[\%]=\frac{A M P P}{J B} \times 100$.

\section{Results}

\subsection{Seasonal validation versus buoys}

Results for the ERA20, ERAI and the calibrated ERA20 reanalyses are shown in Tables 3 and 2, compared to the three measurement buoys for the winter and summer seasons. Seven different statistical indexes are used to compare the different results: Pearson's correlation, bias, the $95 \%$ percentile, the median, the $5 \%$ percentile and the probability of occurrence of waves with height above $5 \mathrm{~m}$ and $7 \mathrm{~m}\left(\operatorname{Pr}_{H_{s}>5 m}\right.$, $\mathbf{P r}_{H_{s}>7 m}$ ). Results for spring and autumn are analogous, but are not shown in Tables 3 and 2 This is because the focus of the paper is on the upper and lower limits.

In summer and winter, correlation is not improved significantly by the calibration method at a $95 \%$ confidence level (marked with an asterisk, '*'). However, there is important improvement of the bias after the calibration in every case, an additional indication that ERA20 underestimates the wave energy. The calibration process corrects significantly this underestimation in cERA20, achieving values similar to those in ERAI. The quantiles also show this underestimation of ERA20, as does the following correction in cERA20, mainly for extreme cases represented by the $95 \%$ percentile. This is an important factor for us, because the computation of the capture width of the device can reproduce important errors if intense events are not properly considered across the implementation of the power matrix. Finally, and related to off-limit events considering wave height instead of wave energy, $\mathbf{P r}_{H_{\mathrm{s}}>7 \mathrm{~m}}$ also shows an improvement via the calibration, although this is not as good as with the previous indicators. ERA20 again underestimates the probability of occurrence of waves above $7 \mathrm{~m}$, registering no extreme $\left(H_{s} \geq 7 \mathrm{~m}\right)$ event at the grid point nearest to Cabo Silleiro, both in winter and summer, while such events were identified after calibration.

\subsection{Wave energy trend maps}

The results of the four trend maps show a clear and expected seasonality. Winter shows the maximum positive trend $(3 \mathrm{~kW} / \mathrm{m} /$ decade) off the west coast of Ireland, while summer shows small trends that are almost negligible in the interior of the Bay of Biscay, the British channel, and the Irish Sea.

If the authors plot the time series of WEF in the grid points nearest to the three buoys, positive trends are evident at the three locations. As expected for the wave trend maps, M1 in winter shows the most significant increase, followed by the buoy at Brittany and, eventually, at Cabo Silleiro. The upper and lower limits of the historical trends are established by winter and summer seasons, with intermediate values observed in spring and autumn. Apart from the historical trends, the evolution of the resource in each season over the last century also shows strong inter-annual variations that can oscillate between 40 and $100 \mathrm{~kW} / \mathrm{m}$ in winter. The summer-winter slopes are $0.17-0.95 \mathrm{~kW} / \mathrm{m} /$ decade for Cabo Silleiro, 0.26-1.86 kW/m/decade for Brittany, and 0.44-2.45 $\mathrm{kW} / \mathrm{m} /$ decade for Galway. These results are totally 
Winter

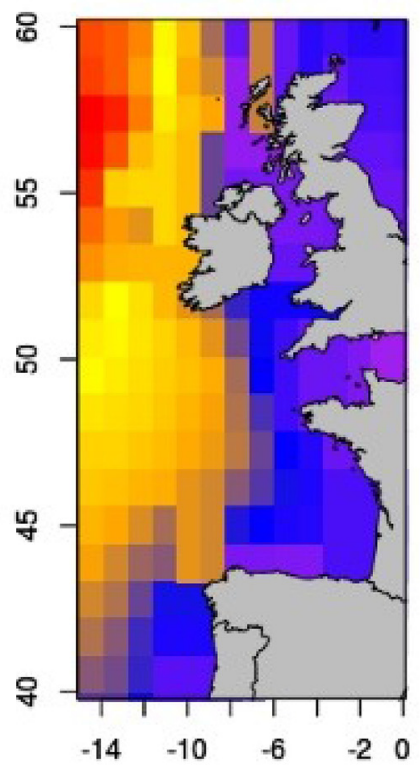

\section{Summer}

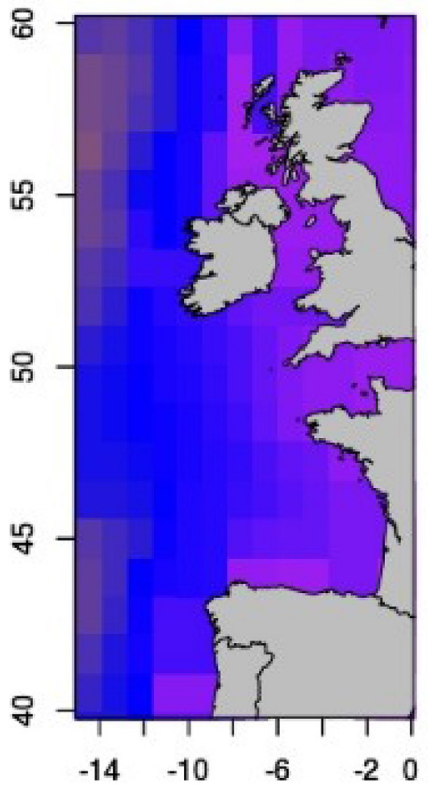

Spring

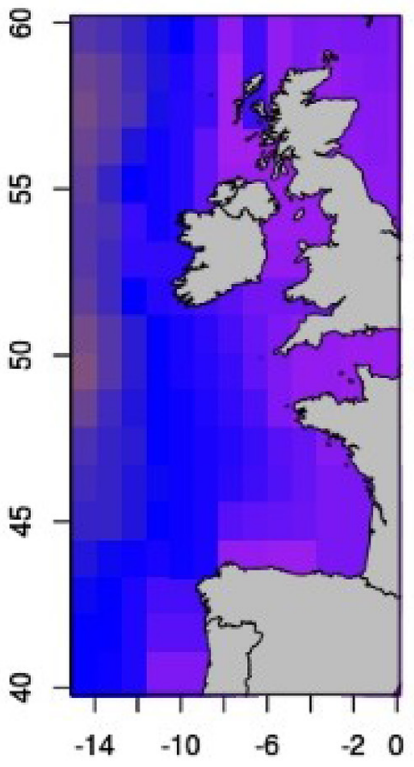

Autumn

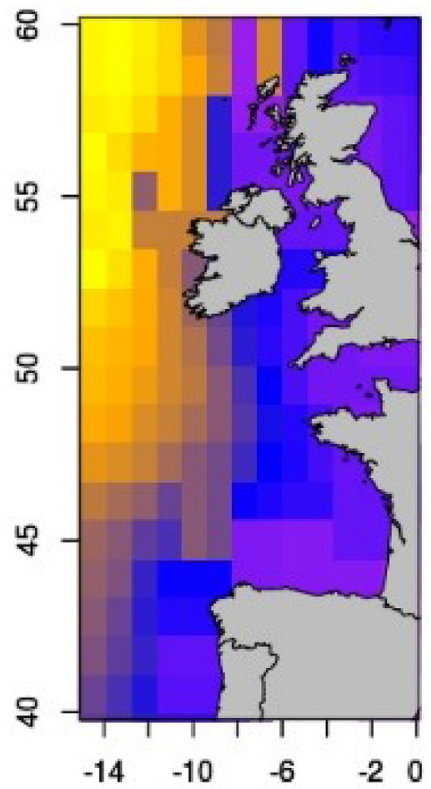

Fig. 4. Seasonal trends of $\mathrm{WEF}(\mathrm{kW} / \mathrm{m} / \mathrm{dec})$ during the last century in the four seasons.

consistent with the seasonal maps previously depicted in Fig. 4.

\subsection{Historical evolution of off-limit events}

Variations of the average resource over the 20th century are reported in Ref. [17], where wave trends show a significant increase of off-limit events. Assuming that OWSCs shift to survival mode in offlimit events, the increase in frequency of off-limit events is demonstrated to affect considerably the power absorption of WECs: up to $60 \%$ less energy from ocean waves in the case of an OWSC [17]. Thus, the operational space of the OWSC is also limited in the present study.
Accurately defining the operational space of a WEC is a very challenging task, where different aspects, such as the design of the PTO system and the mooring lines, can play an important role. Because these aspects are neglected in the present paper, the operational space is limited to the two aforementioned limits: $H_{s}^{M A X}=5 \mathrm{~m}$ and $H_{s}^{M A X}=7 \mathrm{~m}$.

Table 4 shows the frequency of our two kinds of off-limit events as percentages over the five do-decades of the 20th century. Only the nonzero (significant) values of off-limit events are shown in Table 4, neglecting the locations and seasons where the frequency is zero. The most significant increase is observed in Galway and Brittany in the winter season for $\mathbf{P r}_{H_{s}>5 m}$, where off-limit events doubled over the 
Table 4

Occurrence values in percentage for the sea-states beyond the threshold $H_{s}^{M A X}=5 m$ and $H_{s}^{M A X}=7 m$.

\begin{tabular}{|c|c|c|c|c|c|}
\hline Cabo Silleiro, CS & 1900-1920 & $1920-1940$ & $1940-1960$ & 1960-1980 & $1980-2000$ \\
\hline $\mathbf{P r}_{H_{S}>5 m, \text { Winter }}$ & 0.16 & 0.32 & 0.16 & 0.48 & 0.40 \\
\hline Brittany, BT & 1900-1920 & $1920-1940$ & $1940-1960$ & 1960-1980 & 1980-2000 \\
\hline $\mathbf{P r}_{H_{S}>5 m, \text { Winter }}$ & 1.92 & 1.12 & 1.76 & 2.60 & 3.52 \\
\hline $\mathbf{P r}_{H_{S}>7 m, \text { Winter }}$ & 0.00 & 0.12 & 0.04 & 0.16 & 0.36 \\
\hline Galway, M1 & $1900-1920$ & $1920-1940$ & $1940-1960$ & 1960-1980 & $1980-2000$ \\
\hline $\mathbf{P r}_{H_{S}}>5 m$, Summer & 0.00 & 0.00 & 0.08 & 0.16 & 0.15 \\
\hline $\mathbf{P r}_{H_{S}>5 m, \text { Winter }}$ & 3.56 & 2.44 & 2.40 & 3.56 & 6.92 \\
\hline $\mathbf{P r}_{H_{S}>7 m, \text { Winter }}$ & 0.16 & 0.12 & 0.12 & 0.40 & 0.64 \\
\hline
\end{tabular}

Table 5

Hydrodynamic performance of the OWSC measured via the AMPP and the CWR at the three locations described in Table 1 , considering $B=26 \mathrm{~m}$.

\begin{tabular}{lllll}
\hline Locations & WEF $[\mathrm{kW} / \mathrm{m}]$ & AMPP $[\mathrm{kW}]$ & $C W[\mathrm{~m}]$ & CWR [\%] \\
\hline 1. Cabo Silleiro, CS & 16 & 207 & 12 & 47 \\
2. Brittany, BT & 26 & 348 & 14 & 53 \\
3. Galway, M1 & 65 & 823 & 13 & 48 \\
\hline
\end{tabular}

century. These results are consistent with the validation results against buoy measurements in the periods of Table 1.

\subsection{Hydrodynamic performance of the OWSC}

The annual (non-seasonal) hydrodynamic performance of the OWSC is analysed first for the three locations presented in Table 5. For these, scatter diagrams are illustrated in Fig. 6 covering the last do-decade of the 20th century, for analysing the AMPP and the $C W R$ of the device. Table 5 presents the wave power flux, AMPP, CW and CWR in each location for the last do-decade of the 20th century. Only this do-decade is used to compare these results with the results previously published in the literature.

The AMPP results presented in Table 5 vary significantly with the WEF of the location, where absorbed mean power varies from 200 to $800 \mathrm{~kW}$. Similar results are presented in Ref. [85] for an OWSC of comparable dimensions and locations with analogous WEF. In addition, the $C W R$ measures shown in Table 5 lie within a relatively narrow range (48-53\%). Likewise, in the CWR results presented in Ref. [50], bottom fixed OWSCs of similar dimensions show CWR measures of $49-72 \%$, depending on the wave power resource. Therefore, preliminary results of the OWSC are demonstrated to be consistent with other results in the literature.

Hence, AMPP and CWR measures are evaluated over the whole 20th century at the three locations described in Table 1 , considering the resource in winter and summer to study variations of the hydrodynamic performance of the OWSC. Fig. 7 (a), (b) and (c) show these results for Cabo Silleiro, Brittany and Galway, respectively.

For all the different locations, the average power production in winter is significantly higher (over $100 \%$ higher) than in summer. This is to be expected due to the remarkably higher frequency of higherenergy sea-states in winter. However, when evaluating the hydrodynamic efficiency of the OWSC by means of the $C W R$, efficiency is considerably higher in summer, with $C W R$ measures of up to $95 \%$. It should be noted that $C W R$ measures are calculated via Equation (6), using the wave power resource specifically calculated for the season under analysis.

Finally, the frequency of off-limit events increases over the course of the 20th century, particularly in winter, as shown in Fig. 5. This results in slightly higher AMPP estimations, but poorer hydrodynamic efficiencies of the WEC at all the locations, as shown in Fig. 7.

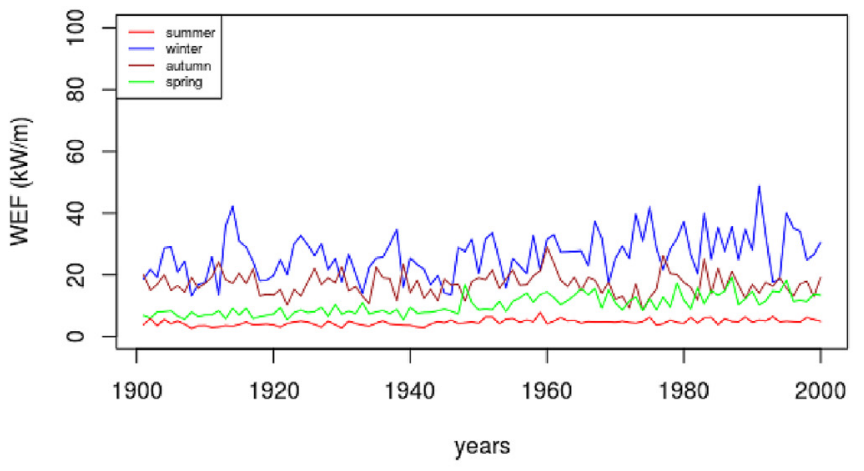

(a) Cabo Silleiro

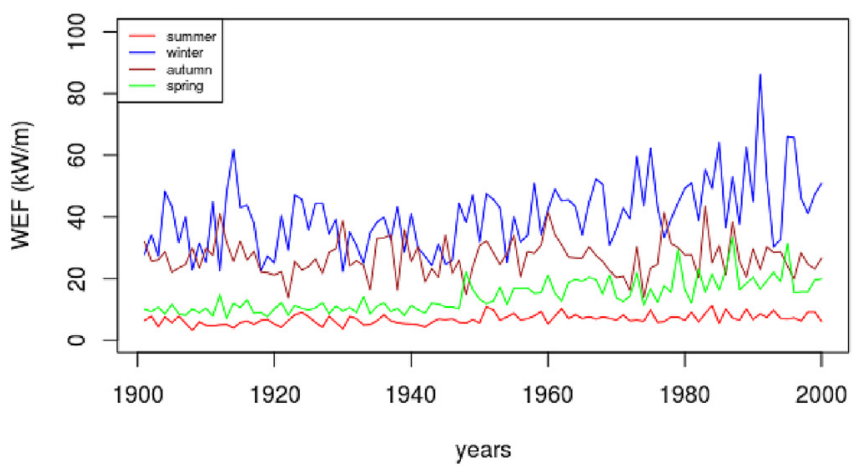

(b) Brittany

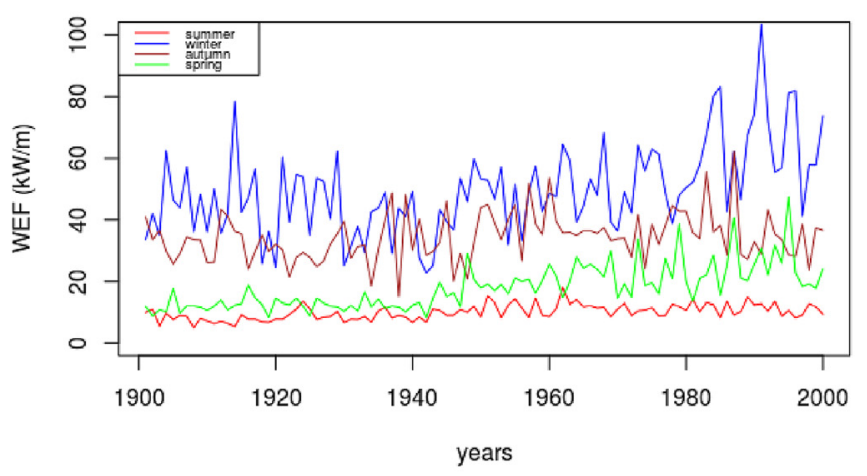

(c) Galway, M1

Fig. 5. Yearly evolution of WEF $(\mathrm{kW} / \mathrm{m})$ during the last century at the three grid points nearest the buoys. 


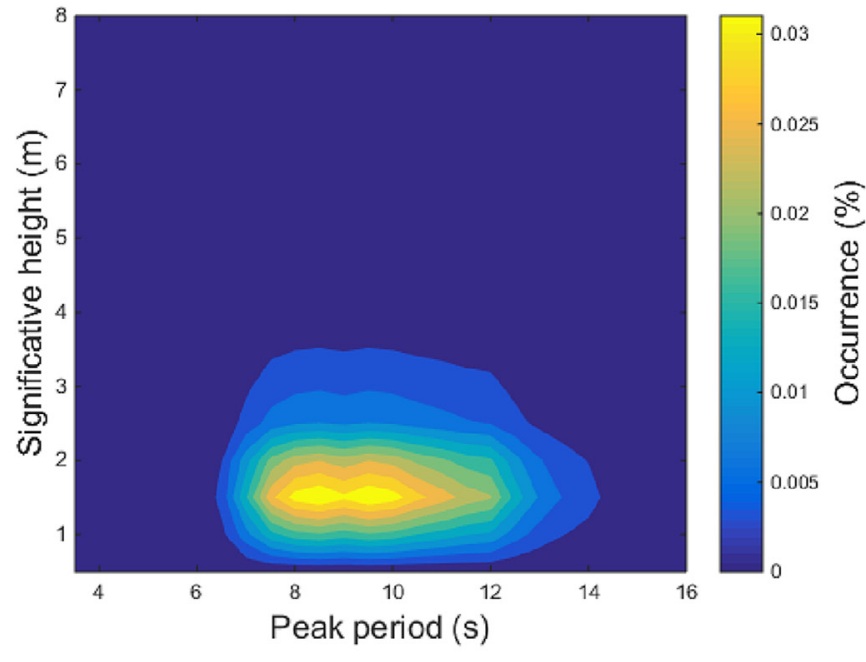

(a) Cabo Silleiro

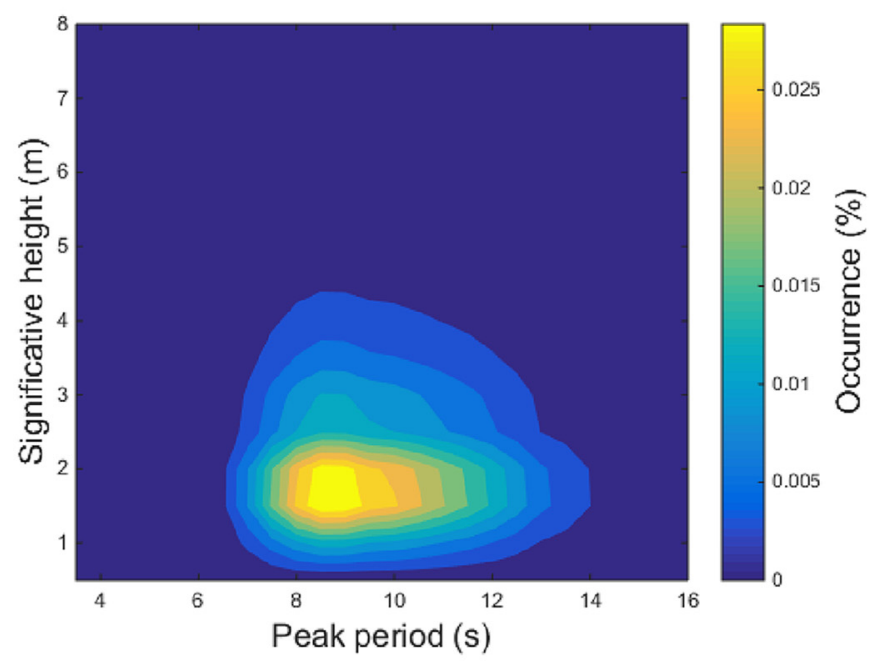

(b) Brittany

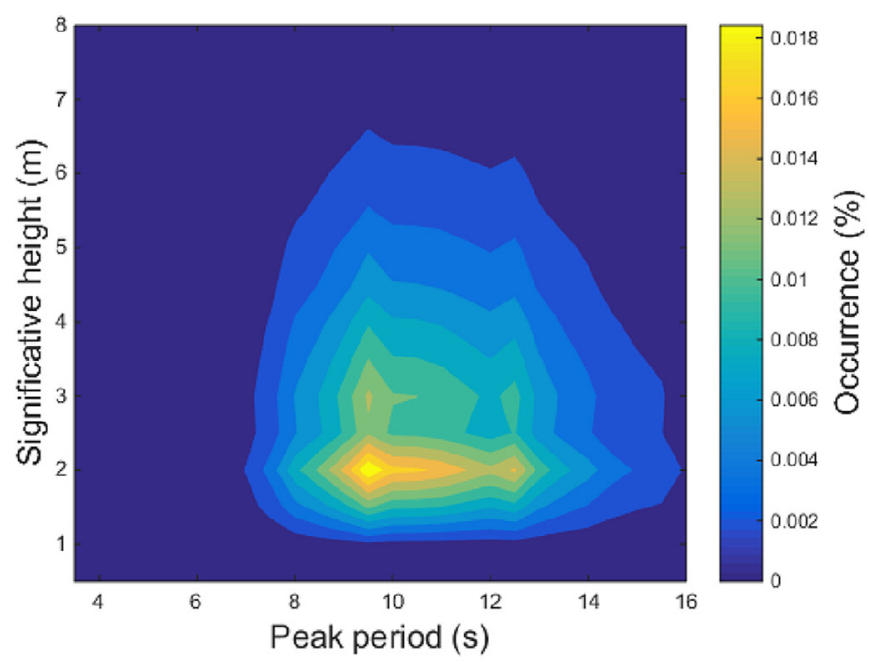

(c) Galway, M1

Fig. 6. Average annual scatter plots of hydrodynamic performance in the last do-decade.

\section{Discussion}

This paper shows that study of the consistency of the wave energy resource should be performed from a long-term perspective, including the influence of wave energy trends. To the best of the authors knowledge, this is an innovative perspective within studies of consistency published in the literature, which have commonly been focused on short or medium term analyses [4,90,91].

In comparison with the authors' previous works on wave energy trends [16-18], the study area in the Atlantic Ocean has been significantly extended, from Ireland to the Gulf of Biscay. Therefore, the validation has been developed against three buoys in this wider area (Bilbao-Vizcaya in the Basque coast, Britanny in the French coast, and M1 in the Irish coast). Furthermore, a new calibration technique is used to obtain the historical wave energy flux series (with periods and heights), creating one transfer function for each season via quantilematching. Therefore, this seasonal calibration is the main novelty, and the consequent computation of wave energy trends for winter, spring, summer and autumn during the last century, together with the seasonally classified validation against the buoy data. To the best of our knowledge, this is the first time trends are seasonally classified and verified. Finally, the influence of these trends is studied not only according to wave energy production of the selected device, but also according to its capacity width. This is a novelty, since it has been studied for short periods until now, and the authors show that the variations of $\mathrm{CW}$ during the decades of the last century are significant, mainly for the trends found for winter.

Thus, as mentioned before, a calibration technique that categorises time series within the four seasons, to obtain a proper transfer function for each season, is used in this paper. A strong positive trend is identified in winter (almost $3 \mathrm{~kW} / \mathrm{m} /$ decade west of Ireland), while the wave trend is slightly weaker in spring/autumn (around $2 \mathrm{~kW} / \mathrm{m} /$ decade in the strongest case) and negligible in summer. This is consistent with the wave height trends mentioned in previous studies $[29,33]$ : if an average wave period of $10 \mathrm{~s}$ (see the most frequent seastates in the scatter plots shown in Fig. 6) is considered and using the WEF results shown in this paper, Equation (1) gives a value of $10 \mathrm{~cm} /$ decade for the strongest wave trend off the west coast of Ireland and south of Iceland. This extreme value of $10 \mathrm{~cm} /$ decade is also consistent with Gulev's measurements [24-26], where a positive trend of 4-8 cm/ decade was observed in the area of study used in this paper.

Apart from the annual positive wave energy trends shown in the three locations, the difference between the summer and winter resources is shown to increase significantly over the 20th century in the Northeast Atlantic ocean. Therefore, the variability of the resource increases substantially. Additionally, the frequency of off-limit events has also increased substantially, doubling the number of off-limit events in winter in Galway and Brittany. This increase of off-limit events partly explains the results shown in Fig. 7, which presents a representative behaviour at each location. To obtain an integral explanation of the results shown in Fig. 7, a linear regression was applied to the AMPP values shown in Table 4, with the aim to identify the approximate trend of the AMPP evolution and compare it to the wave resource's trend at different locations.

1. In Brittany, the increase of AMPP over the 20th century is considerable, increasing 6.3 and $4.5 \mathrm{~kW} /$ decade in winter and summer, respectively. In addition, the occurrence of off-limit events increases substantially, almost doubling over the whole century and increasing over $25 \%$ in the last do-decade. On the contrary, the $C W R$ in Brittany decrease over the 20th century, with a particularly strong reduction in winter (over $20 \%$ during the whole century and almost $10 \%$ in the last do-decade) According to CWR, Brittany is the location with the highest value, summer the season with the highest performance and 1900-1920 the highest do-decade. The device performance was almost $100 \%$. For summer, the increments of the 

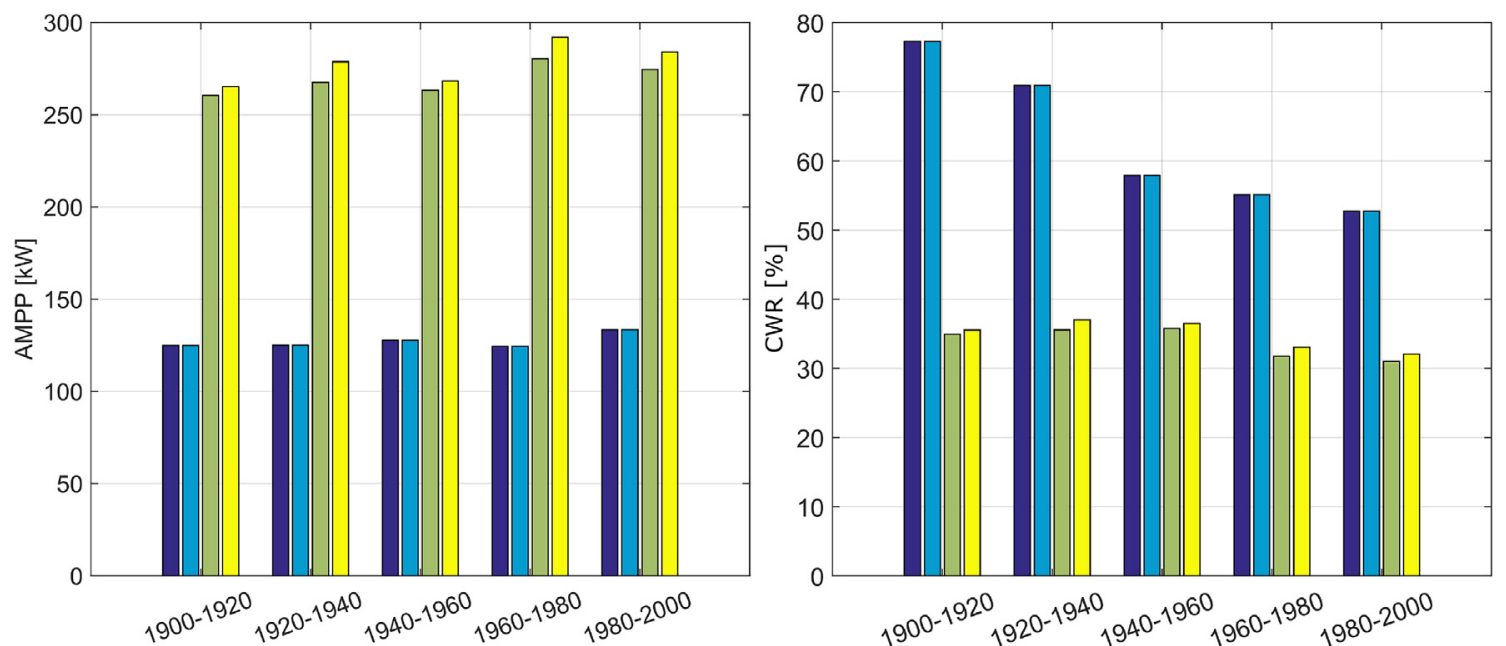

(a) Cabo Silleiro, CS
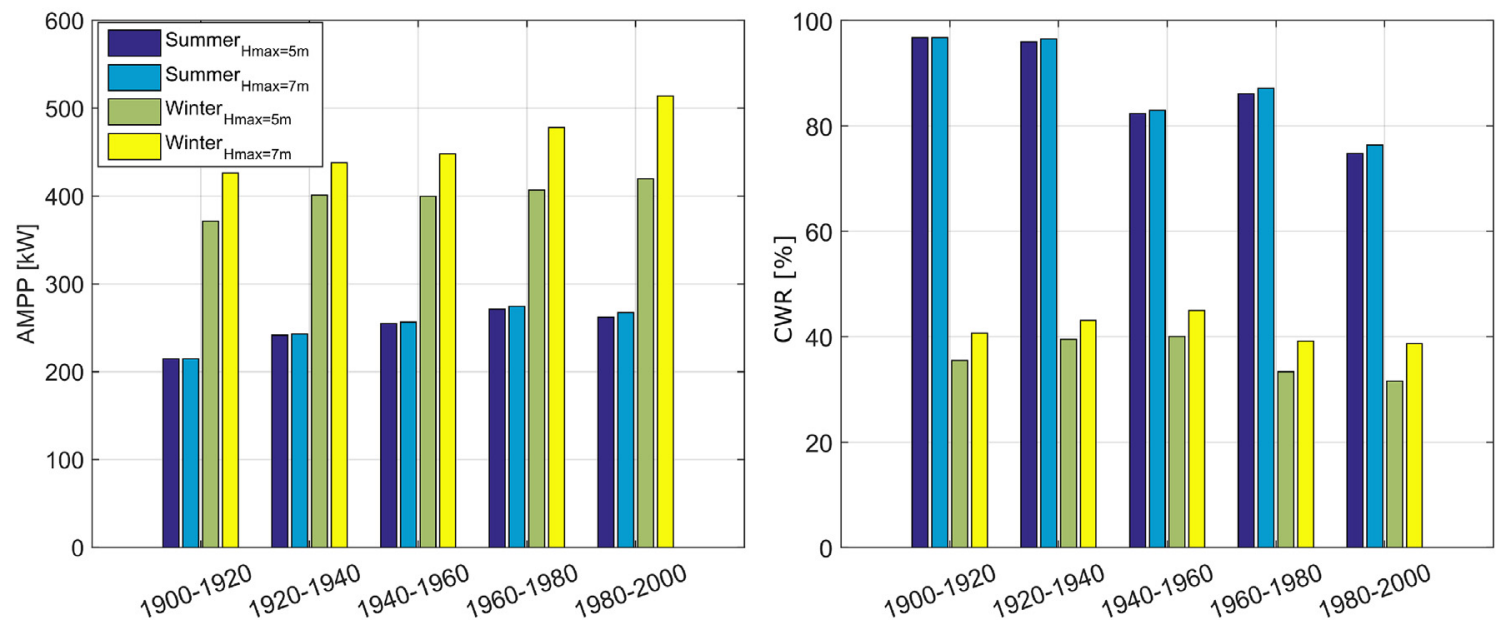

(b) Brittany, BT
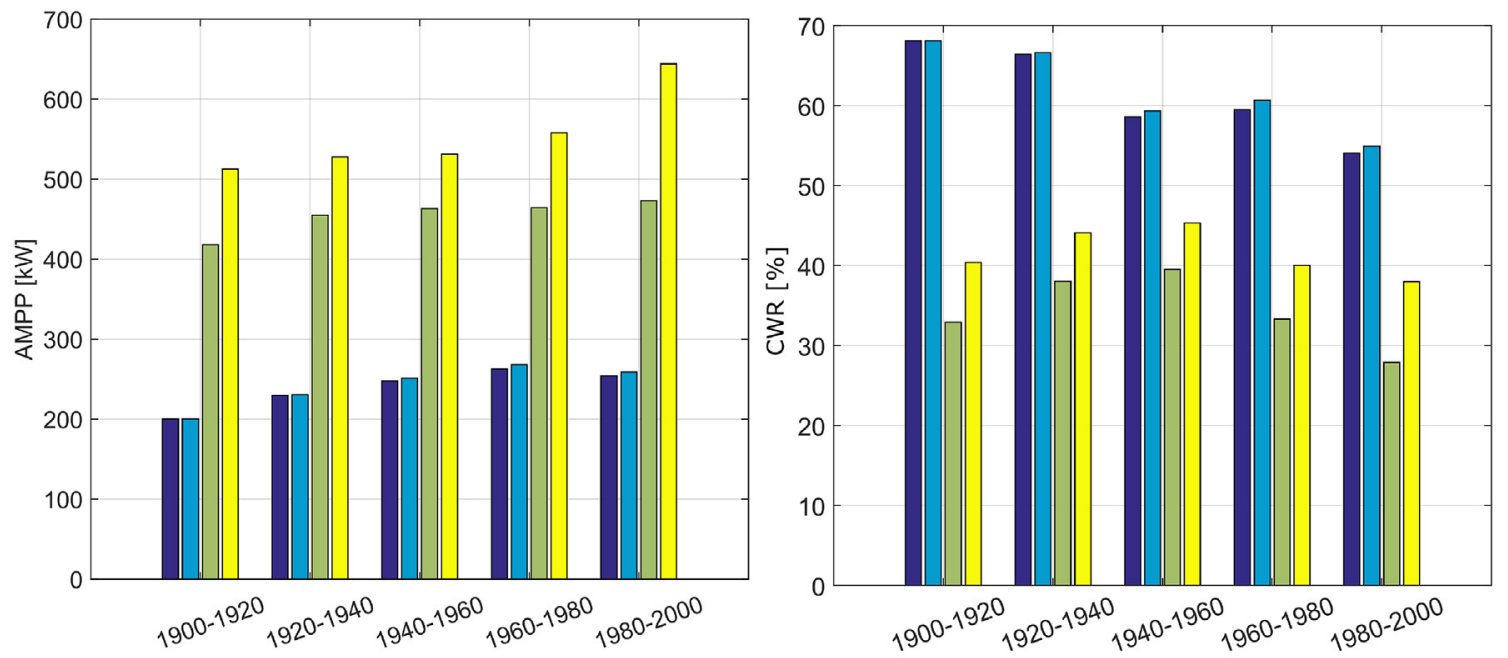

(c) Galway, M1

Fig. 7. Historical evolution of the device's AMPP and CW for summer and winter at the three locations.

WEF (taking into account the width of the OWSC $(B=26 \mathrm{~m})$, using an estimative computation to study the qualitative relationships) are nine times stronger than the increment of AMMP $(1.86 * 26=48.3$ versus $4.5 \mathrm{~kW} /$ decade, approximately nine times higher), and therefore, $C W R$ diminishes throughout the century.

2. Cabo Silleiro shows the weakest positive trends of AMPP in winter (3.4 kW/decade) and summer $(0.8 \mathrm{~kW} /$ decade). The occurrence of off-limit events is also negligible, which is the reason why Table 4 
shows no results for Cabo Silleiro. Although the CWR in summer is lower than in Brittany, the reduction of the CWR is similar to the reduction shown for Brittany (about 20\%). Therefore, in relative terms, it constitutes a stronger loss of performance. This is because the resource trend for the device of $26 \mathrm{~m}$ width is also $0.26 * 26 / 0.8 \approx 9$ times higher.

3. The strongest increments of AMMP appear in Galway, with a significant increase in both winter $(8.1 \mathrm{~kW} /$ decade)and summer (3.5 $\mathrm{kW} /$ decade). Similarly, the occurrence of off-limit events increase significantly in Galway, which results in substantial differences for the AMPP and CWR in winter, between the cases $H_{s}^{M A X}=5 \mathrm{~m}$ and $H_{s}^{M A X}=7 \mathrm{~m}$. Galway is the location with the highest inter-annual (up to $130 \%$ difference between the AMPP in winter and summer), and the highest long-term variation (about 25\% increase of the AMPP). In contrast, the reduction of the CWR is the lowest among the three locations analysed in this paper (about $10 \%$ reduction over the 20th)century. This is because for summer, the resource slope for $\mathrm{B}=26 \mathrm{~m}$ is only 3 times higher: $0.44 * 26 / 3.5 \approx 3$. Although $C W R$ offers only a partial view of the device performance, this long-term consistency of $C W R$ should be noted. This is because Ireland is often considered an inconsistent location for wave energy production due to its high inter-seasonal variability of parameters such as WEF and AMMP [90].

Overall, the wave energy resource in winter is shown to be remarkably higher than in summer. Accordingly, the power absorption corresponding to the winter resource is significantly higher. However, the hydrodynamic efficiency is higher in summer, meaning that a large part of the resource is wasted in winter because WECs must often shift to survival mode (and stop generating power) to protect from critical structural damage. It must be taken into account that the power matrix shown in Fig. 3(b) illustrates the theoretical power absorption capability of the device for all the different sea-states, including those beyond the survival mode limit (set as $H_{s}=5 \mathrm{~m}$ ). However, once the survivability mode limit is incorporated to the power matrix, theoretical absorbed power values beyond that limit default to 0 .

Resource variability is identified as an important cost driver for WECs, because a more consistent wave climate allows for the design of a WEC that can operate close to its optimal operating conditions and maximize the efficiency of the system. Results shown in this paper, where significant differences in WEC hydrodynamic performance are found between summer and winter seasons (based on the measure of $C W R$ ), highlight the problem of designing a WEC that can efficiently absorb the energy stored in ocean waves over the whole year. Therefore, it is demonstrated that, using average wave power resource or other short-term referential values based only on past measurements, to design WECs can be misleading, if annual and even seasonal wave energy trends are ignored, and can result in inefficient WEC designs. In addition, the impact of long-term seasonal wave trends shown in this paper suggest that the selection of ideal locations to install WECs or WEC farms, should not be made based on average wave power measures alone.

This is a study about the past history of wave energy (focusing on the last century), and long-term forecasting is not included, although the general positive trends found after the calibration are coherent with future scenarios of coastal dynamics due to climate change that predicts an increase of both the number and severity of extreme events for wind and waves [37,92].

Regarding WECs, the most extensive estimation of WEC performance so far (only simulations, not on actual devices), indicates that the same technology -for example OWC devices- tends to perform better the more energetic the ocean conditions are. In Ref. [49], authors compare, season by season, the power performance in Iceland and Canary Islands for the same technology and a (simulated) OWC device is almost twice as efficient in Iceland where the WEF is significantly higher in all seasons.
For the Oyster device, according to its designers [93], captured power can be maximized by obstructing the wave with the flap, moving the hinge point close to the seabed, moving the device into shallower water to avoid wave breaking losses and, the most important for this study, optimizing the device's capture width. The authors have demonstrated that this optimization of the capture width should consider annual, and also seasonal, wave energy trends if a lifetime of decades is expected for the device. Average wave power and variability measured over a few decades is not enough to take into account these trends and the consequent optimization.

In summary, the way a WEC is designed should follow decisive economic aspects, since extracting energy from more powerful seastates requires a more resistant device structure and a larger power take-off system, among other characteristics such as mooring lines. However, in this paper, the limitation of the survival mode has been set according to other published literature, without studying its appropriateness for summer or winter resources. The objective of this paper is to highlight the importance of considering this limit when analysing the power assessment of a device especially when the resource, and particularly the magnitude and frequency of extreme events, are demonstrated to increase considerably over the decades. An adequate determination of such a limit requires a more in-depth study, where economical aspects must also be considered.

\section{Conclusions}

The importance of the consistency of the wave energy resource is emphasized in this paper, but from a totally new perspective: the influence of long-term seasonal wave energy trends during the 20th century. Results show a significant reduction of the $C W R$, in the context of positive wave energy trends, which can have substantial consequences when designing a wave energy converter. The steadily increasing differences between the resource for the mildest and strongest seasons, summer and winter, respectively, suggest that the variability of the Northeast Atlantic Ocean increases. In addition, it has been demonstrated that increase of the wave energy resource corresponds, in large part, to increase of off-limit events.

Although the authors have shown the consequences for only a specific device, results are expected to be similar for different type of devices. This is because the main physical reason for the reduction of $C W R$ and consequent performance, is the important positive trend of wave energy during recent decades.

In any case, future work should focus on the analysis of other types of wave energy converters and locations. An example of a new location where a similar analysis could be interesting is Chile (or other Southeast Pacific location), where the wave energy resource has been demonstrated to be more consistent [90].

\section{Acknowledgments}

The authors with the Centre for Ocean Energy Research in Maynooth University are supported by the Science Foundation Ireland under Grant No. 13/IA/1886. This work was also supported by grant CGL2016-76561-R, MINECO/ERDF, UE. Additional funding was received from the University of the Basque Country (UPV/EHU, GIU17/ 002).

\section{References}

[1] Mork G, Barstow S, Kabuth A, Pontes MT. Assessing the global wave energy potential. ASME 2010 29th -International conference on ocean, offshore and -Arctic engineering. American Society of Mechanical Engineers; 2010. p. 447-54.

[2] Falcão A d O. Wave energy utilization: a review of the technologies. Renew Sustain Energy Rev 2010;14(3):899-918.

[3] Ibarra-Berastegi G, Sáenz J, Ulazia A, Serras P, Esnaola G, Garcia-Soto C. Electricity production, capacity factor, and plant efficiency index at the Mutriku wave farm (2014-2016). Ocean Eng 2018;147:20-9. 
[4] Babarit A. Ocean wave energy conversion. first ed. London, UK: Elsevier Ltd; 2016.

[5] Ringwood JV, Bacelli G, Fusco F. Energy-maximizing control of wave-energy converters: the development of control system technology to optimize their operation. IEEE Control Syst 2014;34(5):30-55.

[6] Penalba M, Ringwood JV. A review of wave-to-wire models for wave energy converters. Energies 2016;9(7):506.

[7] Starling M. Guidelines for reliability, maintainability and survivability of marine energy conversion systems: marine renewable energy guides. European Marine Energy Centre; 2009.

[8] De Andres A, Maillet J, Hals Todalshaug J, Möller P, Bould D, Jeffrey H. Technoeconomic related metrics for a wave energy converters feasibility assessment. Sustainability 2016;8(11):1109.

[9] Nielsen K, Pontes T. Generic and site related wave data, Final technical report T021.1. OES-IEA; 2010.

[10] Haces-Fernandez F, Li H, Ramirez D. Wave energy characterization and assessment in the U.S. Gulf of Mexico, East and west coasts with energy event concept. Renew Energy 2018;123:312-22. https://doi.org/10.1016/j.renene.2018.02.047.

[11] Zheng C, Zhuang H, Li X, Li X. Wind energy and wave energy resources assessment in the East China Sea and South China Sea. Sci China Technol Sci 2012;55(1):163-73. https://doi.org/10.1007/s11431-011-4646-Z.

[12] Neill SP, Lewis MJ, Hashemi MR, Slater E, Lawrence J, Spall SA. Inter-annual and inter-seasonal variability of the Orkney wave power resource. Appl Energy 2014;132:339-48.

[13] Sivaramakrishnan T. Wave power over the indian seas during the southwest monsoon season. Energy 1992;17(6):625-7.

[14] Jakimavicius D, Kriauciuniene J, Sarauskiene D. Assessment of wave climate and energy resources in the Baltic Sea nearshore (Lithuanian territorial water). Oceanologia 2018;60(2):207-18.

[15] Ibrahim B, Mahmoud S, Alaraj B. Seasonal sea wave energy at Al-Manara station in Tartous. Energy Procedia 2012;19:104-8.

[16] Ulazia A, Penalba M, Ibarra-Berastegi G, Saenz J. Wave energy trends over the Bay of Biscay and the consequences for wave energy converters. Energy 2017;141(C):624-34.

[17] Penalba M, Ulazia A, Ibarra-Berastegui G, Ringwood J, Sáenz J. Wave energy resource variation o ff the west coast of Ireland and its impact on realistic wave energy converters ' power absorption. Appl Energy 2018;224:205-19.

[18] Ulazia A, Penalba M, Rabanal A, Ibarra-Berastegi G, Ringwood J, Sáenz J. Historical evolution of the wave resource and energy production off the Chilean coast over the 20th century. Energies 2018;11(9):2289.

[19] Galanis G, Chu PC, Kallos G, Kuo Y-H, Dodson CTJ. Wave height characteristics in the North Atlantic ocean: a new approach based on statistical and geometrical techniques. Stoch Environ Res Risk Assess 2012;26:83-103. https://doi.org/10. 1007/s00477-011-0540-2.

[20] WMO. Calculation of monthly and annual 30-year standard normals. wcdp-no. 10. wmo-td/no. 341., Tech. rep. World Metheorological Organization; 1989.

[21] WMO. The role of climatological normals in a changing climate. WCDMP-61, WMOTD/1377, tech. Rep. Word Metheorological Organization; 2007.

[22] Robertson B, Hiles C, Luczko E, Buckham B. Quantifying the wave energy resource and farm siting opportunities for western Canada. Int. Conf. Ocean energy. ICOE 2014); 2014.

[23] Ruggiero P, Komar PD, Allan JC. Increasing wave heights and extreme value projections: the wave climate of the US Pacific Northwest. Coast Eng 2010;57(5):539-52.

[24] S. K. Gulev, V. Grigorieva, Last century changes in ocean wind wave height from global visual wave data, Geophys Res Lett 31 (24). .

[25] Gulev SK, Grigorieva V. Variability of the winter wind waves and swell in the North Atlantic and North Pacific as revealed by the voluntary observing ship data. J Clim 2006;19(21):5667-85.

[26] Gulev SK, Cotton D, Sterl A. Intercomparison of the North Atlantic wave climatology from voluntary observing ships, satellite data and modelling. Phys Chem Earth 1998;23(5):587-92.

[27] Bouws E, Jannink D, Komen G. The increasing wave height in the North Atlantic Ocean. Bull Am Meteorol Soc 1996;77(10):2275-7.

[28] D. K. Woolf, P. Challenor, P. Cotton, Variability and predictability of the North Atlantic wave climate, J Geophys Res: Oceans 107 (C10).

[29] Young I, Zieger S, Babanin AV. Global trends in wind speed and wave height. Science 2011;332(6028):451-5.

[30] Zheng CW, Wang Q, Li CY. An overview of medium- to long-term predictions of global wave energy resources. Renew Sustain Energy Rev 2017;79:1492-502https://doi.org/10.1016/j.rser.2017.05.109.

[31] Reguero B, Losada I, Mendez F. A global wave power resource and its seasonal, interannual and long-term variability. Appl Energy 2015;148:366-80https://doi. org/10.1016/j.apenergy.2015.03.114.

[32] Zheng C, Shao L, Shi W, Su Q, Lin G, Li X, Chen X. An assessment of global ocean wave energy resources over the last 45 a. Acta Oceanol Sin 2014;33(1):92-101. https://doi.org/10.1007/s13131-014-0418-5.

[33] Bertin X, Prouteau E, Letetrel C. A significant increase in wave height in the North Atlantic Ocean over the 20th century. Glob Planet Chang 2013;106:77-83. https:// doi.org/10.1016/j.gloplacha.2013.03.009.

[34] Wang XL, Swail VR. Climate change signal and uncertainty in projections of ocean wave heights. Clim Dyn 2006;26(2-3):109-26.

[35] Cox AT, Swail VR. A global wave hindcast over the period 1958-1997- Validation and climate assessment. J Geophys Res 2001;106(C2):2313-29.

[36] Sterl A, Komen G, Cotton P. Fifteen years of global wave hindcasts using winds from the European Centre for Medium-Range Weather Forecasts reanalysis: validating the reanalyzed winds and assessing the wave climate. J Geophys Res: Oceans
1998;103(C3):5477-92.

[37] Wang XL, Zwiers FW, Swail VR. North Atlantic ocean wave climate change scenarios for the twenty-first century. J Clim 2004;17(12):2368-83.

[38] Kushnir Y, Cardone V, Greenwood J, Cane M. The recent increase in North Atlantic wave heights. J Clim 1997;10(8):2107-13.

[39] Vikebø F, Furevik T, Furnes G, Kvamstø NG, Reistad M. Wave height variations in the north sea and on the Norwegian continental shelf, 1881-1999. Cont Shelf Res 2003;23(3):251-63.

[40] Hurrell JW. Decadal trends in the north Atlantic oscillation: regional temperatures and precipitation. Science 1995;269(5224):676-9. https://doi.org/10.1126/ science.269.5224.676.

[41] H.J.W., Yochanan K, Geir O, Martin V. An overview of the north Atlantic oscillation. American Geophysical Union (AGU); 2013. p. 1-35. https://doi.org/10.1029/ $134 \mathrm{GM} 01$.

[42] Visbeck MH, Hurrell JW, Polvani L, Cullen HM. the North Atlantic oscillation: past, present, and future. Proc. Natl. Acad. Sci. U.S.A 2001;98:12876-7. https://doi.org/ 10.1073/pnas.231391598.

[43] Rogers JC. North Atlantic storm track variability and its association to the north Atlantic oscillation and climate variability of northern Europe. J Clim 1997;10(7):1635-47. https://doi.org/10.1175/1520-0442(1997) 010¡1635:NASTVA ¿2.0.CO;2.

[44] U. Ulbrich, M. Christoph, J. Pinto, J. Corte-Real, Dependence of winter precipitation over Portugal on NAO and baroclinic wave activity, Int J Climatol 19 (4) 379-390.

[45] J. Sáenz, C. Rodríguez-Puebla, J. Fernández, J. Zubillaga, Interpretation of interannual winter temperature variations over southwestern Europe, J Geophys Res: Atmosphere 106 (D18) 20641-20651. http://dx.doi.org/10.1029/2001JD900247.

[46] Wojtysiak K, Herman A, Moskalik M. Wind wave climate of west Spitsbergen: seasonal variability and extreme events. Oceanologia 2018;60(3):331-43.

[47] Robertson B, Hiles C, Luczko E, Buckham B. Quantifying wave power and wave energy converter array production potential. International Journal of Marine Energy 2016;14:143-60.

[48] Neill SP, Vögler A, Goward-Brown AJ, Baston S, Lewis MJ, Gillibrand PA, Waldman S, Woolf DK. The wave and tidal resource of Scotland. Renew Energy 2017;114:3-17.

[49] Rusu E, Onea F. Estimation of the wave energy conversion efficiency in the Atlantic Ocean close to the European islands. Renew Energy 2016;85:687-703.

[50] Babarit A. A database of capture width ratio of wave energy converters. Renew Energy 2015;80:610-28. https://doi.org/10.1016/j.renene.2015.02.049.

[51] Poli P, Hersbach H, Dee DP, Berrisford P, Simmons AJ, Vitart F, Laloyaux P, Tan DG, Peubey C, Thépaut J-N, et al. ERA-20C: an atmospheric reanalysis of the twentieth century. J Clim 2016;29(11):4083-97.

[52] Worley SJ, Woodruff SD, Reynolds RW, Lubker SJ, Lott N. ICOADS release 2.1 data and products. Int J Climatol 2005;25(7):823-42.

[53] Dada OA, Li G, Qiao L, Ma Y, Ding D, Xu J, Li P, Yang J. Response of waves and coastline evolution to climate variability off the Niger Delta coast during the past 110 years. J Mar Syst 2016;160:64-80https://doi.org/10.1016/j.jmarsys.2016.04. 005.

[54] Patra A, Bhaskaran PK. Temporal variability in wind-wave climate and its validation with ESSO-NIOT wave atlas for the head Bay of Bengal. Clim Dyn 2016:1-18.

[55] Kumar P, Min S-K, Weller E, Lee H, Wang XL. Influence of climate variability on extreme ocean surface wave heights assessed from ERA-interim and ERA-20C. J Clim 2016;29(11):4031-46. https://doi.org/10.1175/JCLI-D-15-0580.1.

[56] P. Berrisford, D. Dee, K. Fielding, M. Fuentes, P. Kallberg, S. Kobayashi, S. Uppala, The ERA-interim archive, European Centre for Medium-Range Weather Forecasts.

[57] Sturaro G. A closer look at the climatological discontinuities present in the NCEP/ NCAR reanalysis temperature due to the introduction of satellite data. CDyn 2003;21:309-16. https://doi.org/10.1007/s00382-003-0334-4.

[58] Sterl A. On the (In)homogeneity of Reanalysis products. J Clim 2004;17:3866-73. https://doi.org/10.1175/1520-0442(2004)017<3866:OTIORP > 2.0.CO;2.

[59] Cornes RC, Jones PD. How well does the ERA-Interim reanalysis replicate trends in extremes of surface temperature across Europe? J Geophys Res: Atmosphere 2013;118:10,262-76. https://doi.org/10.1002/jgrd.50799.

[60] Komen GJ, Cavaleri L, Donelan M, Hasselmann K, Hasselmann S, Janssen P. Dynamics and modelling of ocean waves. Cambridge university press; 1996.

[61] J. Bidlot, P. Janssen, S. Abdalla, H. Hersbach, A revised formulation of ocean wave dissipation and its model impact, European Centre for Medium-Range Weather Forecasts.

[62] Poli P, Hersbach H, Dee DP, Berrisford P, Simmons AJ, Vitart F, Laloyaux P, Tan DGH, Peubey C, Thépaut J-N, Trémolet Y, Hólm EV, Bonavita M, Isaksen L, Fisher M. ERA-20C: an atmospheric reanalysis of the twentieth century. J Clim 2016;29(11):4083-97. https://doi.org/10.1175/JCLI-D-15-0556.1.

[63] Maraun D. Bias correcting climate change simulations - a critical review. Current Climate Change Reports 2016;2:211-20. https://doi.org/10.1007/s40641-0160050-x.

[64] P. Reiter, O. Gutjahr, L. Schefczyk, G. Heinemann, M. Casper, Does applying quantile mapping to subsamples improve the bias correction of daily precipitation?, Int J Climatol 38 1623-1633. doi:10.1002/joc.5283. .

[65] Puertos del Estado: Oceanography: Forecast, real time and climate. Madrid: Spanish Government; 2015-10-11. Updated http://www.puertos.es/en-us/oceanografia/ Pages/portus.aspx.

[66] MetOffice UK: Weather and Climatic Shange, MetOffice UK, UK Government: https://www.metoffice.gov.uk/.

[67] Foras Na Mara, Irish Marine Institute, Irish Government: https://www.marine.ie/ Home/search/node/buoys. .

[68] Teutschbein C, Seibert J. Bias correction of regional climate model simulations for hydrological climate-change impact studies: review and evaluation of different 
methods. J Hydrol 2012;456:12-29.

[69] S. Watanabe, S. Kanae, S. Seto, P. J.-F. Yeh, Y. Hirabayashi, T. Oki, Intercomparison of bias-correction methods for monthly temperature and precipitation simulated by multiple climate models, J Geophys Res: Atmosphere 117 (D23).

[70] Lafon T, Dadson S, Buys G, Prudhomme C. Bias correction of daily precipitation simulated by a regional climate model: a comparison of methods. Int J Climatol 2013;33(6):1367-81.

[71] Bett PE, Thornton HE, Clark RT. Using the twentieth century reanalysis to assess climate variability for the European wind industry, theoretical and applied climatology vol. 1. 2015. https://doi.org/10.1007/s00704-015-1591-y.

[72] Panofsky H, Brier G. Some applications of statistics to meteorology. Pennsylvania: Pennsylvania State University; 1958.

[73] Block P, Souza Filho F, Sun L, Kwon H-H. A streamflow forecasting framework using multiple climate and hydrological models. J Am Water Resour Assoc 2009;45(4):828-43. https://doi.org/10.1111/j.1752-1688.2009.00327.x.

[74] Boe J, Terray L, Habets F, Martin E. Statistical and dynamical downscaling of the Seine basin climate for hydro-meteorological studies. Int J Climatol 2007;27(12):1643-55. https://doi.org/10.1002/joc.1602.

[75] Sun F, Roderick ML, Lim WH, Farquhar GD. Hydroclimatic projections for the murray-darling basin based on an ensemble derived from intergovernmental panel on climate change AR4 climate models. Water Resour Res 2011;47(12). https://doi. org/10.1029/2010WR009829. n/a-n/a, w00G02.

[76] Piani C, Haerter JO, Coppola E. Statistical bias correction for daily precipitation in regional climate models over Europe. Theor Appl Climatol 2010;99(1):187-92. https://doi.org/10.1007/s00704-009-0134-9.

[77] Rojas R, Feyen L, Dosio A, Bavera D. Improving pan-European hydrological simulation of extreme events through statistical bias correction of RCM-driven climate simulations. Hydrol Earth Syst Sci 2011;15(8):2599-620. https://doi.org/10.5194/ hess-15-2599-2011.

[78] Applequist S. Wind rose bias correction. Journal of Applied Meteorology and Climatology 2012;51(7):1305-9. https://doi.org/10.1175/JAMC-D-11-0193.1.

[79] Sen PK. Estimates of the regression coefficient based on Kendall's tau. J Am Stat Assoc 1968;63(324):1379-89.

[80] Theil H. A rank-invariant method of linear and polynomial regression analysis, 3 confidence regions for the parameters of polynomial regression equations. Stichting Mathematisch Centrum. Statistische Afdeling 1950:1-16.
[81] Penalba M, Giorgi G, Ringwood JV. Mathematical modelling of wave energy converters: a review of nonlinear approaches. Renew Sustain Energy Rev 2017;78:1188-207.

[82] Cummins W. The impulse response function and ship motion. Schiffstechnik 1962(9):101-9.

[83] Babarit A, Delhommeau G. Theoretical and numerical aspects of the open source BEM solver NEMOH. 11th european wave and tidal energy conference. Nantes, France, EWTEC, no. 08C1; 2015. p. 1-12.

[84] Morison J, Johnson J, Schaaf S, et al. The force exerted by surface waves on piles. J Pet Technol 1950;2(05):149-54.

[85] Babarit A, Hals J, Muliawan M, Kurniawan A, Moan T, Krokstad J. Numerical benchmarking study of a selection of wave energy converters. Renew Energy 2012;41:44-63.

[86] Penalba M, Ringwood J. The impact of wave-to-wire models in control parameter optimisation and power assessment. ASME. Proceedings of the 37th international conference on ocean, offshore and arctic engineering, OMAE, no. OMAE201877501. 2018. p. 1-10

[87] Penalba M, Davidson J, Windt C, Ringwood JV. A high-fidelity wave-to-wire simulation platform for wave energy converters: coupled numerical wave tank and power take-off models. Appl Energy 2018;226:655-69.

[88] Folley M, Whittaker T, Hoff J v. The design of small seabed-mounted bottom-hinged wave energy converter. Procedings of 7 th european wave and tidal energy conf. Porto: EWTEC); 2007.

[89] Budal K, Falnes J. A resonant point absorber of ocean-wave power. Nature 1975;256(5517):478.

[90] Ringwood J, Brandle G. A new world map for wave power with a focus on variability. Proceedings of the 11th european wave and tidal energy conference. European Wave and Tidal Energy Conference; 2015. 2015.

[91] Folley M. The wave energy resource. Cham: Springer International Publishing; 2017. p. 43-79.

[92] Mori N, Shimura T, Yasuda T, Mase H. Multi-model climate projections of ocean surface variables under different climate scenarios? Future change of waves, sea level and wind. Ocean Eng 2013;71:122-9.

[93] Henry A, Doherty K, Cameron L, Whittaker T, Doherty R. Advances in the design of the Oyster wave energy converter. RINA marine and offshore energy conference. 2010. 